\title{
Molecular Subtypes and Clinical Outcomes of Breast Cancer
}

Wasike R.W. MBChB, MMed (Surg) FRCS(C)

Aga Khan University Hospital, Nairobi

Breast cancer is a significant cause of worldwide morbidity and mortality in females (1). A major challenge in the diagnosis and treatment of breast cancer is its heterogeneity, because individual breast tumours can exhibit tremendous variations in clinical presentation, disease aggressiveness and treatment response (2). Breast cancers can also display strikingly distinct clinical characteristics in different patient and ethnic populations (3). For example, in Caucasian populations, most breast cancers occur in post-menopausal women at a mean and median age of 60 and 61 years respectively (4). In contrast, a bimodal pattern of incidence, beginning at age 40 is seen in both Asian and African population such as those seen in Singapore and Kenya (5-8).

Gene expression profiling in tumour tissues suggest that breast cancers may be subdivided into two subtypes consisting of two estrogen receptor (ER) - positive types, (Luminal A and Luminal B) and three (ER) negative subtypes. (Human epidermal growth factor receptor 2 - expressing, Basal like (ER-ve PgR-ve and Her2-ve) triple negative, "Normal like" - Un classified. All these subtypes have distinctive clinical outcomes (9-11).

Specifically, luminal A tumours, characterized by positive ER/PgR and negative HER2, show the most favourable clinical features among the five subtypes. Luminal B tumours express HER1/HER2 in addition to ER/PgR, show less favourable clinical outcomes compared with luminal A tumours. Basal-like tumours are characterized by the expression of cytokeratins 5/6 (CK 5/6) and CK17 and are prevalent in patients with BRCA1 mutations (11). Basal like and HER2 - over-expressing groups both are ER/PR - negative and have been associated with poor clinical features and survival.

Data suggests that molecular profiles in breast cancer are generally fixed at inception (12). Therefore, exposures that influence the risk of developing breast cancer might be related to the tumour. Molecular profiles later affect the biology and clinical behaviour of the tumours that arise.

Some early work has started in earnest at both the AKUH(N) and Kijabe Hospitals to try and stratify our breast cancer patients to those mentioned subtypes to help in both diagnosis and treatment. The limiting factors are small numbers of patients expense to undertake the tests and lack of both internal and external validation (13).

We should feel encouraged to carry on the work and give our patients individualized breast cancer care based on their known molecular subtypes that well and clearly determine their clinical behaviour and outcome.

\section{References}

1. Chia KS, Seow A, Lee HP, Shanmugaratnam K. Cancer incidence in Singapore, 1993-1997. In Singapore cancer registry report 5. Singapore: Singapore Cancer Registry, 2000.

2. Travassoli FA, Schnitt SJ. Pathology of the breast. New York: Elsevier; 1992.

3. Wiencke JK. Opinion: impact of race/ethnicity on molecular pathways in human cancer. Nat Rev Cancer 2004;4(1):7984.

4. Giuliano AE. Breast. In: Tierney LM, McPhee SJ, Papadakis MA, editors. Current medical diagnosis and treatment, 37th ed. Stamford:Appleton and Lange; 1998. p 666-90.

5. Ferlay J, Parkin DM, Pisani, P., editors. GLOBOCAN: cancer incidence and mortality worldwide. International Agency for Research on Cancer (IARC) Cancer Base 3. Lyon, France: IARC; 1998.

6. Yu H, Jin F, Shu XO, et al. Insulin-like growth factors and breast cancer risk in Chinese women. Cancer Epidermol Biomark Prev 2002; 11:705-12. 
7. Fung LF, Wong N, Tang N, et al. Genetic imbalances in pT2 breast cancers of Southern Chinese women. Cancer Genet Cytogenet 2001; 124: 56-61.

8. Perou CM, Sorlie T, Eisen MB, et al. Molecular portraits of human breast tumours. Nature 2000;406:747-52.

9. Sorlie T, Tibshirani R, Parker J, et al. Repeated observation of breast tumor subtypes in independent gene expression data sets. Proc Natl Acad Sci USA 2003;100:8418-23.

10. Nielsen TO, Hsu FD, Jensen $K$, et al. Immunohistochemical and clinical characterization of the basal-like subtype of invasion breast carcinoma. Clin Cancer Res 2004;10:5367-74.

11. Carey LA, Perou CM, Livasy CA, et al. Race, breast cancer subtypes, and survival in the Carolina Breast Cancer Study. JAMA 2006;295:2492-502.

12. Lacroix M, Toillon RA, Leclercq G. Stable 'portrait' of breast tumors during progression: data from biology, pathology and genetics. Endocr Relat Cancer 2004;11:497-522.

13. Gakinya et al (in this issue) 